\title{
CATEGORÍAS DE TIEMPO HISTÓRICO
}

\author{
Alberto CEBAllos HoRNERO \\ Universidad de Cantabria \\ David Ceballos Hornero ${ }^{1}$ \\ Universidad de Barcelona
}

En la civilización clásica griega, base del pensamiento occidental actual, la idea de tiempo se concibió bajo la oposición entre Chrónos, sucesión temporal que dura, y Kairós, instante fugitivo de la oportunidad. Estas representaciones sirven para caracterizar dos versiones del tiempo histórico: como tiempo cronológico y como tiempo rizomático, donde la diferencia estriba en el énfasis en el análisis y en la narración respectivamente.

\section{INTRODUCCIÓN}

En el presente artículo se analiza la unidad temporal utilizada por los historiadores. Para el historiador el tiempo es una categoría aristotélica, un ente real que necesita para situar o contextualizar los acontecimientos. El tiempo en el análisis histórico es diferente del utilizado en la Física, ya que en esta última el tiempo se equipara a una magnitud que describe la continuidad y la duración del movimiento. El paso del tiempo es, de esta manera, para el físico una mera ilusión inventada cuyo fin es poder caracterizar el movimiento (lo real). Sin embargo, para el historiador lo "inventado" es la dinámica histórica y su duración, puesto que la establece él de forma subjetiva; en cambio, la ordenación y contextualización de los acontecimientos le "viene dada» (según las fuentes disponibles en el presente), siendo el tiempo, entonces, una dimensión real en donde se locali-

${ }^{1}$ Departamento de Matemática Económica, Financiera y Actuarial de la Universidad de Barcelona. Av. Diagonal 690, 08034 Barcelona. Tfno: +34 9340219 51, Fax: +34 4034892 . ceballos@ub.edu 
zan los hechos históricos, y a partir de la cual el historiador puede inferir sus teorías de explicación del pasado congruentes con la información y la perspectiva presentes. Por tanto, la sucesión histórica de acontecimientos tiene la misma ordenación para cualquier observador, no así la sucesión física de movimientos salvo que sea causal ${ }^{2}$.

La sucesión histórica se puede analizar, como mínimo, desde dos posiciones temporales. Por un lado, desde un tiempo cronológico de datación y ordenación de los acontecimientos seleccionados a partir del cual describir cuantitativamente los hechos y relacionar la evolución histórica. La otra posición es la definición de un tiempo rizomático como una simultaneidad reversible de sucesiones que se interrelacionan entre ellas y en el tiempo a modo de espirales ${ }^{3}$.

Desde el presente, el análisis histórico en tiempo cronológico impone una sucesión lineal irreversible en su interpretación, derivada de una concepción acumulativa de los acontecimientos. Es decir, la equivalencia de la Historia con una memoria escrita sumativa que va incorporando, y por tanto acumulando, los nuevos acontecimientos relacionados con el sujeto histórico ${ }^{4}$ sus intereses. Por el contrario, en el análisis en tiempo rizomático la simultaneidad permite cierta reversibilidad de la sucesión y contextualizar un estudio sincrónico particular con otros acontecimientos anteriores, paralelos y/o posteriores. El análisis histórico, en este último caso, muestra una dependencia histórica de la trayectoria seguida (no del valor acumulado) en la evolución de los acontecimientos, no determinista ni fija, sino que se va «autoconstruyendo" a partir de las relaciones (con-

${ }^{2}$ Davies, P.: Sobre el tiempo. Crítica. Barcelona, 1996, pp. 210-217. Un estudio sintético acerca del papel del tiempo en todas las disciplinas científicas está contenido en Ceballos Hornero, D.: Análisis del Tiempo como variable en Economia Financiera. Tesis Doctoral, Universitat de Barcelona. 2004, pp. 13-64.

3 Zavala, I.: «Hacia una tipología de los tiempos». Ludus vitalis, 1999, vol. VII, n 12, pp. 171 181 , describe toda una tipología temporal entre las que confrontamos el tiempo lineal cronológico con el rizomático. El tiempo rizomático representa una simultaneidad de ritmos entrelazados de manera compleja (espirales), que son reversibles (principios y finales intercambiables) en el contexto de análisis (historiografía, música, poesía, vida cotidiana, Posmodernidad...). El tiempo rizomático en historiografía es policrónico o la consideración de sucesiones (relatos) simultáneas e interrelacionadas, pero referentes a diferentes evoluciones (según perspectiva, personaje, materia...) en un mismo contexto.

4 Sea una persona, las generaciones de una familia, un grupo, una entidad colectiva, un espacio... 
textos) y de la simultaneidad de sucesiones (evoluciones) que se van narrando. Es decir, la memoria escrita entendida como proceso condicionado a cómo se ha ido escribiendo, adaptándose consecuentemente a la evolución de los intereses del sujeto histórico.

Estas dos posiciones temporales se nutren de ideas grecorromanas y, en concreto, se pueden ver sus bases en la deificación del tiempo de la civilización griega. El análisis de las categorías de tiempo histórico desde su analogía con la deificación griega se presenta en tres partes: una primera de vinculación teórica entre Tiempo e Historia, seguida de la descripción de la trilogía divina griega del tiempo, para acabar con la interpretación de las categorías de tiempo histórico en la tercera parte.

\section{TIEMPO E HISTORIA}

Teniendo en cuenta sus relaciones con el presente, la Historia se puede concebir como la descripción de un sistema ${ }^{5}$ : la información geográfica, etnológica, demográfica, económica, cronológica... Tomada como descripción, la Historia, utiliza el tiempo matemático, tiempo demiurgo que permite construir la sucesión de acontecimientos y plantearla como el análisis de cuadros sincrónicos y cronológicos. La secuencia histórica e irreversible del tiempo (del pasado hacia el futuro pasando por el presente) permite el análisis anterior, al ser el tiempo una cualidad o propiedad independiente del contenido agrupado en los anteriores cuadros ${ }^{6}$. Sin embargo, desde una visión sociológica de la Historia se rechaza el tiempo exógeno y matemático, defendido entre otros por $\mathrm{F}$. Braudel $\mathrm{l}^{7}$, como la unidad de análisis. E. Durkheim y M. Halbwachs defendieron una categorización del concepto tiempo por parte de cada grupo social. M. Halbwachs argumentaba que los grupos sociales construyen sus recuerdos, apareciendo una memoria colectiva, que los individuos recuerdan, pero que el grupo determina cómo será recordado. Se ve así el tiempo como un producto social, siendo una dimensión particular de una determinada realidad social que se contempla ${ }^{8}$.

5 Mosterín, J.: Conceptos y teorías de la ciencia. Madrid. 1984, pp. 131-133.

'Guriévich, A.: Las categorias de la cultura medieval. Madrid, 1990, p. 51.

7 Braudel, F.: La Historia y las Ciencias Sociales. Madrid, 1968, p. 99, Bachelard, G.: Dialectique de la Durke. Paris.

${ }^{8}$ Burke, P.: Formas de Historia Cultural. Madrid, 2000 (1997), pp. 65-69. 
La Historia nace con los primeros relatos, donde la escritura tenía la función de conservar la memoria, convirtiendo este relato de hechos al historiador en un maestro de la memoria ${ }^{9}$. Memoria escrita que documenta los acontecimientos públicos en beneficio de los actores y la posteridad, y contra el olvido del tiempo $^{10}$.

La memoria hace referencia a las categorías de tiempo y de ser. Sin embargo, la memoria en su concepción original, en la Grecia Antigua, no se relacionaba con el tiempo. No suponía una conciencia del pasado o interés por el mismo, sino que simplemente formaba parte del aprendizaje (individual o de grupos pequeños) y se insertaba dentro de ejercicios espirituales, poéticos, adivinatorios y de salvación (inmortalidad) ${ }^{11}$. La memoria en el mundo griego era, pues, pasiva y sin relación directa con la conciencia del pasado. Aristóteles distinguía la memoria como poder de conservación del pasado de la reminiscencia o recuerdo voluntario ${ }^{12}$. Es decir, la memoria no pertenecía a la facultad de pensar salvo por accidente. Los griegos la situaban entre las pasiones y los sentimientos con relación a la poética, divinizándola por su importancia en una civilización oral $^{13}$.

La visión tradicional de la memoria con la Historia es a través de la función del historiador de custodiar el recuerdo público de los acontecimientos, documentándolos en beneficio de los actores (su gloria) y su posteridad (aprendizaje positivo o negativo). Pero esta memoria escrita es difícil de calificar como objetiva y se caracteriza, o bien individualmente por su construcción por un sujeto, o bien colectivamente a partir de la reconstrucción del pasado por parte de un grupo. La memoria se concibe como maleable, interesando, desde el análisis his-

9 Bermejo Barrera, J.C.; P.A. Piedras Monroy: Genealogia de la Historia. Ensayos de Historia tebrica III. Madrid, 1999, p. 10.

${ }^{10}$ Esta conquista del pasado, guardando de manera escrita los recuerdos, supone una difícil invención humana en palabras de Meyerson, I.: "Le temps, la mémoire, l'histoire". Journal de Psychologie, 1956, p. 335.

11 Vernant, J.-P.: Mito y pensamiento en la Grecia Antigua. Barcelona, 2001 (1965), p. 116.

12 Aristóteles: Acerca de la memoria y de la reminiscencia, 449b 6 y 451 a 20.

13 Mnemosyne, madre de las musas en las teogonías griegas, dispensa un saber de tipo adivinatorio, el cual descansa sobre la confianza en la memoria individual. Así, los pitagóricos tenían la obligación de retener todo como un ejercicio de memoria. Vernant, J.-P.: Op. cit., pp. 89134. 
tórico, su transmisión y cómo cambian los recuerdos públicos en el tiempo, además de sus usos y olvidos en el tiempo ${ }^{14}$.

La relación de la memoria con el tiempo surgió mediante el olvido, el cual se contrapone a la liberación que supone el ejercicio de memoria respecto al devenir y a la muerte. Así, el olvido queda ligado, en la Antigua Grecia, al tiempo humano, al tiempo de la condición mortal que nunca se detiene. El tiempo, dios Chrónos del envejecimiento, el pitagórico Parón lo igualaba al rey de la ignorancia porque engendraba el olvido antes que el aprendizaje y el recuerdo ${ }^{15}$. El olvido marca el límite o la temporalidad de la memoria e introduce el tiempo como una cualidad de la uimperfección" humana ${ }^{16}$. En él también se puede ver un vínculo con la importancia de la muerte o de la temporalidad como tema histórico, puesto que el olvido hace efímero a cualquier acontecimiento, ser, objeto... perecedero. El olvido pertenece a los vencedores, pues los derrotados no pueden permitirse olvidar lo que ocurrió, generando una memoria negativa como característica de su historia, e incluso de su identidad ${ }^{17}$. Esta amnesia histórica por parte de los vencedores se materializa en la supresión oficial de recuerdos conflictivos en beneficio de la cohesión social, sea entre grupos diferentes o dentro de un mismo grupo. Es decir, el vínculo entre historia y memoria no es simple e introduce el tiempo a través del olvido de la pasajera vida humana.

Para los griegos el tiempo se relacionaba con el estar ${ }^{18}$ al tener un modo de pensar intemporal. Concebían el tiempo en función de un presente. Así, Hesíodo primer autor que utilizó un esquema temporal en sus obras, en su Teogonía muestra un tiempo implícito en la sucesión de generaciones: de oro, de plata, de hierro. Homero en la Iliada utiliza ya un tiempo cronológico en el que datar y ordenar los acontecimientos, quedando implícito un tratamiento de la Historia como crónica, es decir, la idea aristotélica de estudio de lo particular vinculado a los asuntos humanos y temporales.

14 Se admite la existencia de una memoria histórica de tipo negativa, es decir, que sirve de advertencia ante la repetición o la analogía con recuerdos almacenados de situaciones o dinámicas con resultados perversos o desfavorables en el pasado, para el grupo o el sujeto histórico. La importancia y uso de esta memoria va cambiando según la sucesión de acontecimientos favorables o desfavorables, que afecta a la percepción del riesgo de repetición.

${ }^{15}$ Aristóteles: Física IV, 13, 222b.

${ }^{16}$ Ricoeur, P.: La Mémoire, l'histoire, l'oubli. Seuil, Paris, 2000 b, p. 536.

17 Burke, P.: Op. cit. 2000(1997), p. 79.

${ }^{18}$ Ferrater Mora, J.: «Tiempow. Op. cit., pp. 3.494-3.509. 
El recuerdo de acontecimientos pasados, reales o mitológicos, dio lugar a la narración histórica en la Grecia Clásica cuando Heródoto y Tucídides entendieron el relato como un todo relacionado, superando lo efímero del acontecimiento - instante ${ }^{19}$, mediante la retórica de comprensión de la totalidad del conjunto de acontecimientos seleccionados a través de causas explicativas ${ }^{20}$. Era una narración de las gestas de los héroes para que su gloria perdurara en la posteridad. El tiempo, en estas obras, muestra su relación mítica con el Eterno Retorno al buscar que perdurase eternamente lo narrado.

A partir de Heródoto y Tucídides la Historia empieza a considerarse como un proceso de investigación racional como descripción y narración de acontecimientos a partir de una actitud crítica, frente a la res gestae o mera enunciación de los hechos pasados con una cronología variable ${ }^{21}$.

Esta totalidad narrativa que supone una relación de sucesión de los acontecimientos durante la época del dominio romano del Mediterráneo deja de ser un relato local o de un pueblo (el griego y sus héroes). La narración histórica de Polibio es un ejemplo de relato global o integrador de los acontecimientos y circunstancias de todos los pueblos del Mediterráneo dominados. La nueva concepción histórica de este griego es recogida por Tito Livio en sus escritos sobre las gestas romanas, introduciendo la idea de Roma Aeterna $a^{22}$. Es decir, se avanzó hacia el análisis descriptivo de una época o la vinculación sucesiva de acontecimientos, diferenciándose del relato y de la crónica de acontecimientos puntuales.

Con la difusión del cristianismo y su filosofia sobre un tiempo lineal, aparece la narrativa histórica de progreso/retroceso, quedando al margen las teorías del «eterno retorno" de inmortalidad de los héroes, sobre todo a partir de San Agustín y Plotino ${ }^{23}$. El tiempo pasa a ser algo creado, sin preceder o ser consus-

19 Instante no considerado como la medida física precisa de un presente cada vez más corto por las nuevas tecnologías de la información y de medición en tiempo-real, sino de un instante contextualizado al relato.

${ }^{20}$ Bosch Veciana, A.: «Els orígens grecs de la investigació històrica». La Historia. IV Col loquis de Vic. Barcelona, 2000, pp. 102-103.

${ }^{21}$ Hernando, C.: "La medida del tiempo y la construcción de la historia" en VV.AA. Dos milenios en la Historia de España. Año 1000, año 2000. Madrid, 2000, p. 48.

22 Bermejo Barrera, J.C.; P.A. Piedras Monroy: Op. cit., 1999, pp. 15-17.

${ }^{23}$ Turetzky, P.: Time. London, 1998, p. 56. 
tancial a la Creación, que se dirige hacia la muerte, donde la eternidad se sitúa después de la muerte y antes de la vida.

La idea de proceso lineal (temporal) se extendió con la difusión de las ideas cristianas y su preconización del "Día del Juicio Final" o "Fin del Mundo». De este modo, el relato histórico pasa de concebirse en un tiempo mítico y eterno a describirse cronológicamente. La memoria de hechos pasados, reales o mitológicos, se describe como una sucesión orientada hacia un fin recogido en una tendencia de progreso o decaimiento. El cristianismo impuso en la cultura occidental una concepción globalizadora de la historia, como un proceso unitario y dotado de sentido desde la Creación hasta el Juicio Final por la Encarnación del hijo de Dios en hombre ${ }^{24}$. Se pasa así de la narración individual a la abstracta (generalización).

En la siguiente fase de esta evolución del papel del tiempo en la producción historiográfica, J.C. Bermejo Barrera distingue tres tipos de historia incompatibles entre sí: la humanista de sesgo renacentista y esencialmente retórica, moralista y política; la historia novelada que busca el entretenimiento; y, por último, la erudita, que es jurídica, religiosa y filológica ${ }^{25}$. En otras palabras, la distinción entre el cuento, la novela histórica y la historia teórica (académica).

El último tipo de historia es la que se expande a partir del siglo XIX, dando lugar a la historia como ciencia y encumbrando como principal instrumento formal de análisis la cita documental y bibliográfica. El historiador deja de ser un referente objetivo de su relato, y se convierte en un investigador que recopila fuentes: documentos y monumentos, que aporten credibilidad a su relato ${ }^{26}$. De esta manera, la historia deja de ser simple descripción avalada por argumentos de autoridad y la memoria, y pasa a ser una narración reforzada por fuentes documentales y técnicas de crítica externa del documento, juntamente con una crítica interna de la verosimilitud del contenido del documento.

P. Burke distingue en las últimas fases de la evolución del papel del tiempo en la producción historiográfica una alternancia entre la relevancia de la narra-

${ }^{24}$ Hernando, C.: Op. cit., p. 50.

${ }^{25}$ Bermejo Barrera, J.C.: El final de la Historia. Ensayos de Historia Teórica I. Madrid, 1987, p. 36 .

${ }^{26}$ Bermejo Barrera, J.C.: Op. cit. 1987, p. 78. 
ción del acontecimiento y el énfasis en la descripción de la sucesión de acontecimientos ${ }^{27}$. Teniendo en mente la diferencia entre el relato tradicional de los acontecimientos relevantes y la crítica de la Ilustración de que la Historia era más que la narración de los acontecimientos, en el siglo XIX la Historiografía vuelve a poner en el centro el acontecimiento defendiendo la crónica que lo describe. En el siglo XX la escuela de los Annales ataca la historia episódica ${ }^{28}$ y defiende un análisis de las estructuras seculares en la sucesión de los acontecimientos. La escuela de los Annales, tras la sucesión de M. Bloch y L. Febvre por F. Braudel, contextualizó el análisis en un tiempo social (perturbación, coyuntura o estructura) que se oponía al acontecimiento, haciendo hincapié no en el individuo (descripción), sino en el "hecho social en su totalidad ${ }^{29} "$.

El análisis de las estructuras sociales como una evolución marxista de la Historia es criticada por el estatismo que implica, porque es un análisis generalista de las propiedades que vinculan temporalmente los acontecimientos que no incluye la intención y carácter particular de los mismos. Pero la narración del acontecimiento no es la «solución» porque no se refiere al entorno sucesivo del mismo y puede caer el relato en la ficción por la subjetividad del historiador.

P. Burke señala como camino de solución una nueva narrativa moderna que una el análisis de problemas y estructuras en el tiempo con la narración de cada acontecimiento, denominándolo "narrativa densa ${ }^{30}$ ». P. Burke ve intentos de esta

27 Burke, P. [editor]: Formas de hacer Historia. 1994 (1991). Madrid, pp. 287-305.

${ }^{28}$ Para F. Braudel, por ejemplo, el trabajo de los historiadores no se reduce a contar historias, ya que el relato pasa por alto tanto factores explicativos del contexto histórico como elementos ajenos a los protagonistas como el modo de pensar de la gente corriente o el marco económico y social, y también tiende a personificar entidades colectivas como países, organizaciones, etc., para que tengan cabida en la línea argumental del relato.

${ }^{29}$ Ricoeur, P.: Tiempo y narración I. Configuración del tiempo en el relato histórico. México, 2000a (1983a), p. 180.

${ }^{30}$ Burke, P.: Op. cit., 1994(1991), pp. 297-298. La narración densa responde al problema, según P. Burke, de hacer una narración lo suficientemente densa como para tratar no sólo la serie de acontecimientos e intenciones conscientes de sus agentes, sino también las estructuras - intuiciones, modos de pensamiento, etc. - tanto si dichas estructuras actúan como freno de los acontecimientos o como acelerador. P. Ricoeur (Temps et Récit III. Le temps raconté. Paris, 1983c) y J.F. Lyotard (La condition postmoderne. Paris, 1979) también ven una unificación de la descripción sucesiva del análisis de estructuras con la narración del acontecimiento puntual. El primero defendiendo que todo se reduce a alguna forma narrativa y el segundo a través de la noción de Gran Narrativa, que generaliza la narración al análisis estructural de los acontecimientos. 
narrativa moderna de unión del acontecimiento borroso con la emergencia de estructuras en la actual novela histórica y de ficción con la invención de la conciencia de los personajes, la aparición dentro del relato de varios puntos de vista (personajes con "vida" propia), el reflejo intencionado, a modo de advertencia, de la subjetividad u óptica del historiador/escritor y la consideración de acontecimientos generadores, en la terminología de E. Le Roy Ladurie, que revelan cambios estructurales en sus culturas contemporáneas.

P. Burke, sin embargo, parte de la narrativa densa como una descripción precisa buscando una interpretación no únicamente crónica y partiendo de la retórica del acontecimiento ${ }^{31}$. Como ejemplos de esta narrativa densa se pueden poner a la micronarración de acontecimientos en un escenario local, pero contextualizándolos con las tendencias generales de la dinámica sucesiva histórica, o al relato hacia atrás de la historia, que vincula el tiempo público de los acontecimientos (memoria colectiva, tendencias generales) con el tiempo privado de cada personaje, evento, estructura... principal (tiempo interno de la retórica).

A lo largo de este repaso se ha puesto de manifiesto la utilización de dos conceptos de tiempo: uno rizomático, con una simultaneidad de diferentes narraciones, que se ha ido alternando con otro cronológico, de la cuantificación objetiva de los análisis históricos.

El primer tiempo nació con la función narrativa, la cual no es ni una alternativa ni similar al binomio de explicación - comprensión puesto que no utiliza el "porque» en sentido causal ni finalista. Para P. Ricoeur, las experiencias humanas se organizan y clarifican mediante su narración con un carácter eminentemente temporal, es decir, desde un principio a un final ${ }^{32}$, sea una descripción analítica de una estructura, sea el relato de una época a partir de un acontecimiento generador. El lenguaje occidental ordena los textos temporalmente a

${ }^{31}$ Retórica que se vincula con las metáforas o ideas preconcebidas en la memoria colectiva o en la forma narrativa, ya que como defienden Lakoff, G.; M. Johnson: Metdforas de la vida cotidiana. Madrid, 1986 (1980), el lenguaje condiciona el pensamiento y viceversa. Toda palabra, expresión, narrativa de cada situación, en conjunto la retórica utilizada conlleva unos precondicionamientos en su entendimiento según cada cultura, grupo social...

32 Todo lo que se cuenta ocurre en el tiempo y supone tiempo, sea Historia o ficción. Ricoeur, P.: Temps et Récit III. Le temps raconté. Paris, $1983 \mathrm{c}$. 
través de la estructura verbal de pasado, presente y futuro, y de los adverbios temporales. El verbo es un generador de un orden temporal de los acontecimientos $\mathrm{y}$ acciones ${ }^{33}$. La narración o la función narrativa, consecuentemente, consiste en marcar, organizar y clarificar las experiencias temporales ${ }^{34}$, de manera que un acontecimiento no es una simple ocurrencia sino también un potencial elemento narrativo. La narración identifica al individuo en el relato de sus hechos. El tiempo histórico, por tanto, se relaciona con el tiempo de la narración ${ }^{35}$. La construcción narrativa que supone la Historia se hace desde la imaginación, la cual permite al historiador enlazar desde el presente el pasado recontado.

El tiempo rizomático permite, por tanto, la convivencia de distintas narraciones en la explicación o justificación de los acontecimientos y su contexto. Es una superación de la mera datación crónica de los acontecimientos y permite una narración y una descripción contextualizada de las relaciones históricas presentes en un acontecimiento. El tiempo cronológico surgió con la historia serial de la sucesión de la información histórica cuantificada, la cual se ordena y se vincula funcional o causalmente mediante un tiempo crónico de constatación del inicio, duración y dirección de los acontecimientos y su sucesión ${ }^{36}$. Permite, así, una vinculación de cada acontecimiento con las tendencias históricas constatadas y justificando el éxito o fracaso de los mismos por la estructura del contexto en que ocurren, sin considerar la voluntad y el poder de los protagonistas.

\section{DEIFICACIÓN TEMPORAL GRIEGA}

En las sociedades primitivas la comprensión del tiempo no era una coordenada neutral, como lo es el tiempo de la Física, sino poderosas y misteriosas fuerzas que gobernaban todas las cosas. Por eso estaban cargadas de valores emocionales: el tiempo podía ser bueno o malo, propicio u hosti ${ }^{37} . .$. , siendo un elemento presente en la mitología humana.

${ }^{33}$ Díaz Tejera, A.: «Tiempo físico y tiempo lingüístico en Aristóteles». Opera selecta. 2000, pp. 137-152.

${ }^{34}$ Kearney, R.; M. Rainwater.: The continental philosophy reader. London. 1996, pp. 138-139.

${ }^{35}$ Ricoeur, P.: Op. cit., 1983c, p. 166. Para P. Ricoeur el tiempo histórico es un vínculo indirecto entre la historia y la narración por la intencionalidad del pensamiento del historiador.

${ }^{36}$ Correspondería al tiempo histórico de P. Ricouer y el de F. Braudel.

${ }^{37}$ La simbología humana lleva a plantear una analogía visual entre el macrocosmos que imagina y el microcosmos en el que vive, así las imágenes divinas tienen claros rasgos humanos y liga- 
Se puede ver en la gran mayoría de las culturas primitivas una idea temporal cíclica implícita en sus creencias, pinturas, "calendarios", etc. ${ }^{38}$, donde destacaba el "estar". Aunque en la cultura griega se pueden observar ciertos rasgos de un tiempo lineal sobre todo en la lírica ${ }^{39}$ y la tragedia ${ }^{40}$, dirigiéndose hacia un final (la muerte), es la cultura hebrea, con su inicio (venida del Mesías) y final (Juicio final) universales, y con su tendencia irreversible hacia el final, la que mejor representa y difunde la idea de tiempo lineal; concepción que con la expansión del cristianismo se hace común en casi todas las civilizaciones.

La dualidad temporal actual con una idea cíclica (eterno retorno, calendario) y otra lineal (reloj), no fue común hasta la Edad Media. Sí, la deificación del tiempo en las culturas antiguas representaba únicamente una concepción cíclica, por la importancia en aquella época de las cosechas, los efectos estacionales y climáticos, y la explicación de la sucesión día-noche ${ }^{41}$.

Durante la Época Clásica se recurría a la Mitología para la explicación de fenómenos y conceptos. Pero, por más que la Mitología sea casi en su totalidad un tejido continuo de fábulas, no por ello deja de poseer una utilidad incontestable a la hora de aclarar la mentalidad o cosmovisión en el mundo antiguo y por ende el imaginario colectivo actual (memoria) ${ }^{42}$. De este modo, los mitos continúan vivaces en el imaginario colectivo, inspirando nuevas y renovadas interpretaciones de nuestro mundo espiritual e intelectual (S. Freud, C.G. Jung, ...) ${ }^{43}$.

dos con la Naturaleza, apareciendo el tiempo como un anciano. Guriévich, A.: Op. cit., pp. 54-55 y 81-82; y Le Goff, J.: Tiempo, trabajo y cultura en el Occidente Medieval. Madrid. Taurus, 1983 (1978).

38 VV.AA.: “Time». The new Encyclopaedia Britannica. 1986, p. 654.

39 J.-P. Vernant: $O p$. cit., p. 109 , siguiendo a B. Snell, sefiala que con el nacimiento de la poesía lírica aparece una nueva imagen del hombre en el mundo griego, abandonando el ideal heroico y surgiendo valores directamente ligados a la vida afectiva del individuo, los cuales están sometidos a todas las vicisitudes de la existencia humana: placeres, emociones, juventud..., que tienen por colorario una experiencia del tiempo que ya no se encuadra con el modelo de un devenir circular.

${ }^{40}$ La muerte, la desesperación o la felicidad como porvenir sustituyen a la eternidad.

${ }^{41}$ Mangas, J.; S. Montero [coord.]: El Milenarismo. La percepción del tiempo en las culturas antiguas, Madrid. 2001, pp. 3-4.

42 Frenzel, E.: Diccionario de argumentos de la literatura universal. Madrid, 1976.

${ }^{43}$ García Gual, C.: "Los mitos griegos y su proyección literaria” [Curso Magistral de la Universidad Internacional Menéndez Pelayo]. Santander, 2000. 
En la mitología griega el tiempo se relacionaba con el problema del cambio y con el movimiento, sin quedar claro la diferencia entre los mismos ${ }^{44}$. Esta relación se conceptualizó bajo una trilogía divina:

1. Aibn, dios del tiempo absoluto y perfecto que representa la eternidad.

2. Chrónos, dios del tiempo en tanto que dimensión empírica, o sea, su medi$\mathrm{da}^{45}$. Por ello es móvil, limitado e imperfecto, o en palabras de Platón (Timeo 37) es sólo la imagen de la eternidad.

3. Kairos, como el momento favorable (la oportunidad) no regular.

Aion representaba en un principio el tiempo de vida, y por extensión, la duración de ésta; pero terminó por designar la Eternidad, la duración sin principio ni final como totalidad simultánea de todos los tiempos. Esta identificación de Aión con la Eternidad ya está presente en la obra de Heráclito ${ }^{46}$. La Eternidad es una presencia simultánea y no sucesiva, es decir, no queda definida por la enumeración de sus partes ${ }^{47}$, por lo que es transcendente o está más allá del tiempo. Teniendo en cuenta este aspecto, los griegos la concibieron como un tiempo perfecto frente a su imagen (Chrónos) caracterizada por ser un tiempo imperfecto o una presencia sucesiva. La relación entre ambos es la misma que la del espejo con la imagen que se refleja, de manera que Aión y Chrónos (espejo e imagen) se necesitan para existir el tiempo. Dadas las ideas asociadas a este personaje mítico, Aión fue personificado bajo dos formas diferentes en la Antigüedad: por un lado, un viejo, señor del tiempo, de lo inmutable (eterno) y perfecto, y por otro lado, como un joven sosteniendo un zodíaco a través del cual circulaban las estaciones (movimiento ć́clico que simbolizaba la perfección del movimiento) ${ }^{48}$.

${ }^{44}$ Aristóteles en Física IV, II, 220b comentaba que el tiempo se medía por el movimiento, pero también el movimiento por aquél. Numeraba el movimiento según el antes y el después (el cambio). Platón en el Timeo identifica el tiempo con el movimiento circular.

${ }_{45}$ Abad Casal, L.: «Horae, tempora anni y la representación del tiempo en la antigüedad romana". Anas, n ${ }^{\circ} 7 / 8,1994 / 95$, p. 81.

${ }^{46}$ Campillo, A.: «Aión, Chrónos y Kairós: la concepción del tiempo en la Grecia Clásica». La otra Historia, $\mathrm{n}^{\circ} 3,1991$, p. 40.

47 Borges, J.L.: Historia de la Eternidad. Buenos Aires, 1953.

48 Le Glay, M.: Lexicon Iconographicum Mythologiae Classicae (LIMC). Vol. I, 1980, pp. 409411. 
Chrónos (Saturnus en el panteón romano) personificaba, en cambio, el tiempo cronológico, de la sucesión ordenada (lo que miden los relojes). Era el dios del envejecimiento y se relacionaba con la agricultura (estaciones y calidad cosecha). Según la Mitología griega nació de la Tierra y del Cielo, provocando la separación definitiva entre lo divino (Cielo) y lo terrestre (Tierra) al impedir que la unión entre éstos fuese fecunda de nuevo mediante la castración de su padre $e^{49}$. Con ello se dio paso al orden cósmico frente al caos primigenio. Chrónos tras castrar a su padre se erigió en soberano y juez de los mortales que poblaban la Tierra, pues, como dios del tiempo, veía todo lo pasado y lo venidero, repartiendo y equilibrando suerte y fortun $a^{50}$. En este contexto, fue concebido como un rey sabio bajo cuyo mandato predominó la abundancia y la justicia ${ }^{51}$. Por ello, esta divinidad solía ser representada con aspecto de un anciano, o al menos de una persona adulta, $y$ siempre en una postura pensativa ${ }^{52}$.

Chrónos fue derrocado a su vez por su hijo Zeus, lo que supuso según la Mitología griega el fin de la armonía, del orden y de la supremacía de los dioses sobre los humanos ${ }^{53}$.

El término Chrónos fue utilizado por Homero para designar un cierto intervalo de tiempo ${ }^{54}$, pero posteriormente alude a todas las duraciones finitas, de tal manera que acabó denominando la sucesión en su más abstracta universalidad. Así pues, era un tiempo que se caracterizaba por lo móvil, lo finito y lo imperfecto. Es el tiempo que se puede numerar, o sea, medir por un reloj. Chrónos sig-

${ }^{49}$ Bonnefoy, Y. [dir.]: Diccionario de las mitologias. Vol. 2, 1996, pp. 100-101 y 358-359.

${ }^{50}$ Conti, N.: Mitologia. Murcia, 1988.

${ }^{51}$ Hesíodo en Los trabajos, 117-118, describió la abundancia de la Edad de oro en la que reinaba Chrónos.

52 Daremberg, M.C.; Saglio, E.: Dictionaire des Antiquites Grecques et Romaines (DAGR). 1969 y ss., vol. 3(1), pp. 1.084-1.090.

${ }_{53}$ Chrónos en las primeras teogonías griegas de Hesiodo y Ferecides es un Titán hijo del Cielo, o de Zeus en Ferecides, y de la Tierra, quien castra a su padre y devora a sus hijos, excepto a Zeus en Hesiodo, para encumbrarse y permanecer en el poder. Este Titán era el organizador del cosmos, designado por Krónos. Sin embargo, más tarde, debido seguramente a la semejanza fonética con una de las palabras para designar el tiempo, se identifica a este Titán, dios del envejecimiento, con el tiempo, concepto sofisticado para el siglo VI a.C. cuando aparecen las primeras teoginías. Turetzky, P. 1998 Time, pp. 5-6; y Kirk, G.S. et alii: Los Filosofos Presocráticos. Gredos, 2001 (1957), pp. 83-113.

${ }^{54}$ Campillo, A.: Op. cit., p. 39. 
nificaba el tiempo común de los humanos, con un principio y un final; es la idea cientifica y lógica del tiempo que siglos más tarde asumió la Ciencia como concepto temporal. Por consiguiente, representaba la extensión al concebirse como unidad temporal del período (mensurable y numerable) y de la sucesión (argumentación, causalidad y explicación). Pero también, Chrónos era la personificación de la noción de tiempo como el factor oscuro del orden universal ${ }^{55}$ y hubo quien lo identificó con el Éter al ser único ${ }^{56}$. De Chrónos como dios temporal nace los contrarios del Cielo y la Tierra, macho y hembra, de manera que se puede interpretar el tiempo como la unidad que transciende los contrarios ${ }^{57}$.

Finalmente, y frente al tiempo representado por Chrónos, los antiguos griegos utilizaban la palabra Kairós para denotar el momento favorable o la oportunidad idónea. Por Kairós los antiguos griegos entendían un intervalo de tiempo relativamente breve; pero no era el instante o presente actual (nyn) del que manan Chrónos y $\mathrm{Ai}^{\mathrm{i}} \mathrm{n}^{58}$, sino el momento adecuado o favorable. Kairós era el "punto justo" para Homero, rodeado de cierta aureola ética para Hesiodo ${ }^{59}$. En la Grecia Clásica era asociado a la primera cualidad del atleta, esto es, aprovechar la oportunidad para vencer ${ }^{60}$. Por otro lado, para Platón (Nomoi IV, 709, b7) Kairós estaba relacionado con la aritmética y la geometría, indicando el ideal de "valor medio", la moderación o el equilibrio. Este es el tiempo de las intenciones y de los fines en la terminología del filósofo E. Jaques ${ }^{61}$. Es el tiempo de la actividad humana, de las decisiones, dado que Kairós tiene que ver con kainos: lo nuevo, la innovación.

Kairós representaba el momento en que la acción humana acababa de encontrar un proceso natural que se desarrollaba al ritmo de su propia duración. Es el tiempo de la operación técnica, que no dejar escapar la oportunidad. Así, Platón señala que el artesano jamás debe abandonar su tarea bajo pena de dejar pasar el Kairós y ver la obra estropeada ${ }^{62}$. La técnica está sometida al Kairós, que es incapaz de dominar sin inteligencia.

\footnotetext{
Daremberg, M.C.; Saglio, E.: DAGR, p. 1.084.

Conti, N.: Op. cit., p. 122.

Vernant, J.-P.: Op. cit., p. 108.

58 Campillo, A.: Op. cit., pp. 58-60.

59 Moreno, P.: LIMC. Vol. V., pp. 920-921.

60 Daremberg, M.C.; Saglio, E.: DAGR, p. 787

${ }^{61}$ Jaques, E.: La forma del tiempo. Barcelona, 1984(1982).

62 Platón: La República, II, 370 b y 374c.
} 
Kairós no representa un instante privilegiado, sino el momento favorable. El acontecimiento no tiene lugar porque tuviese que ocurrir en ese preciso instante por la "presión" del entorno y del pasado, sino porque alguien aprovechó sus oportunidades u otros no las aprovecharon. Kairós supone el riesgo de actuar y tener éxito o fracasar, no "la llamada del destino".

El arquetipo de la imagen de Kairós era el de un adolescente masculino esquivo, alado, calvo y/o con un característico mechón de pelo a modo de largo flequillo, que corre, sobre ruedas o con pies alados, y que sostiene una balanza desequilibrada con su mano izquierda ${ }^{63}$. Estos rasgos reflejaban la concepción del momento favorable como un hecho que sólo ocurre una vez (adolescente virginal), que era inútil tratar de retenerlo (corre sobre ruedas o con pies alados), diffcil de atrapar (sólo por el flequillo delantero) y que una vez pasado ya no se puede recuperar (es calvo por el cogote para no poder ser atrapado una vez que ha pasado). Calístrato (Descripciones 6,4), comentando la estatua de esta divinidad sita en Sición, lo expresa en los siguientes términos: "Nos pareció francamente una maravilla; además, uno de nosotros, gran sabio en arte y conocedor de cómo descubrir las maravillas de la técnica de los artistas, nos hizo el razonamiento de los recursos empleados, explicándonos la oportuna técnica observada en esta obra. Según él, las alas de los pies están ahí para indicar la agudeza y mostrar que, recorriendo la eternidad, lleva consigo las estaciones; en cuanto a su joven belleza indica que la belleza es siempre oportuna y que la oportunidad es el único artífice de la belleza, y además que todo lo marchito queda fuera de la naturaleza de lo oportuno; en cuanto al cabello bajando por la frente, indica que así como es fácil de coger cuando se acerca, una vez que se ha ido y el momento idóneo para las acciones ya ha pasado, una vez desdeñada pues, ya no es posible volver a atrapar a Oportunidad ${ }^{64} \%$.

De esta manera, en la Grecia clásica el tiempo se concebía bajo tres aspectos diferentes: el ideal de perfección inmutable y no sucesiva, Aión o la Eternidad entendida como un presente simultáneo de todos los tiempos; su imagen imperfecta, Chrónos o tiempo que pasa como una sucesión abstracta en el que trans-

${ }^{63}$ Moreno, P.: LIMC, pp. 922-926.

64 Traducción de Francesca Mestre: Calistrato. Descripciones, Biblioteca Clásica Gredos n 217. Madrid, 1996, pp. 374-375. 
curre la vida, lo móvil; y, finalmente, el momento de la acción humana, que no dejar escapar la oportunidad, personificado en Kairós o momento favorable en la acción, determinante sobre todo en la operación técnica.

Teniendo en cuenta la trilogía divina griega sobre el tiempo y el vínculo temporal de la Historia, se puede afirmar como expuso E. Meyer ${ }^{65}$ que la Historia depende de tres voluntades: de la selección de acontecimientos (para hacerlos eternos), de la relación entre acontecimientos (su sucesión y duración) y del aprovechamiento de las ocasiones (momento favorable).

\section{CHRÓNOS Y KAIRÓS APLICADOS AL TIEMPO HISTÓRICO}

Hemos visto la alternancia de la narración del acontecimiento y del análisis de la estructura en la primacía del análisis histórico. Ambas posiciones denotan una diferente perspectiva en cuanto a la unidad temporal: la primera alternativa supone un tiempo rizomático de simultaneidad del acontecimiento con los ritmos y sucesiones de sus personajes y su entorno, simultaneidad reversible para poder narrar la dinámica histórica de cada hecho, época... La segunda alternativa implica un tiempo cronológico de descripción y análisis cuantitativo del acontecer, tomado serialmente. Es un tiempo irreversible y lineal que impone relaciones hacia delante en la sucesión numerada. Se pueden poner como instrumentos temporales característicos de cada alternativa al reloj interno, cuyas agujas avanzan y retroceden al ritmo marcado por la narración, frente al calendario externo, que data y ordena sucesivamente los acontecimientos para su explicación lineal. Así, el calendario pareciera que fuese invención del cronista como indicaría su origen en la señalización de los momentos de cosecha y pago de deudas, mientras el reloj fuese invención del investigador u observador en su intento de imponer un sistema de medida, interno o externo, de la dinámica de lo observado.

La Historia desde sus orígenes ha explicado el Pasado de la Humanidad cual reflejo de los acontecimientos que se han vivido socialmente, es decir, poniendo el énfasis en la sucesión más que en el instante. Los acontecimientos son orga-

65 E. Meyer defiende en El historiador y la historia antigua. Madrid, 1955 (1910), la importancia de la voluntad, de selección, constitución, de decisión..., en los elementos históricos. 
nizados según un orden de ocurrencia marcado por un calendario y un reloj externos. En la Sociedad de los últimos siglos prevalece una noción abstracta del tiempo, lo que se ha traducido en una ordenación temporal de todo hecho, y asimismo, en una visión de sucesión de dichos acontecimientos ordenados. En otras palabras, el investigador pone el énfasis en el período y en la duración más que en el instante. Todo ello se puede interpretar como una de las razones por las que la Historiografía analiza el pasado desde la causalidad, buscando una explicación para todo hecho histórico que lo relacione con los anteriores y con los posteriores cronológicamente, describiendo así el mismo. En otras palabras, el historiador realiza una interpretación racional del pasado, donde las relaciones que se establecen constituyen la memoria de cada época en tanto que se analizan como la influencia de los acontecimientos pasados sobre el o los estudiados ${ }^{66}$. Desde la racionalidad, aquello que no es posible vincular lógicamente con su entorno temporal cercano se tiene o bien por una falsedad, o bien por un error, o bien por un hecho ajeno al proceso de evolución humana que refleja la Historia. Por consiguiente, se niega en parte la libertad de decisión y de acción humanas, por cuanto que las decisiones y acciones han de ser racionales siguiendo un orden causal, como si estuvieran determinadas por el entorno social e histórico de los períodos en que se tomaron ${ }^{67}$. De esta manera, parece que la Historia académica transforma los documentos en monumentos (memoria colectiva), aislando, agrupando, relacionando, constituyendo, etc., los elementos pertinentes. Pero la Historia narrativa con su interés por el acontecimiento no pone tanto peso en la causalidad como vínculo entre acontecimientos, sino más bien la voluntad e interés de los protagonistas.

El trabajo del historiador se centra en la representación y la interpretación a través del relato y las huellas o fuentes, documentales o no. Cuando se entiende como una descripción de una sucesión lineal de acontecimientos relacionados, la cual delimita la duración de los mismos, se caracteriza el tiempo cronológicamente, simbolizado en el mito griego de Chrónos. En cambio, la narración del

${ }^{66} \mathrm{~J}$. Elster defiende adicionalmente una explicación intencional de la racionalidad, es decir, la explicación de la realización de un comportamiento o de un suceso en función del objetivo o meta que se pretende lograr. La explicación intencional comprende la relación entre acción, deseo y creencia. Elster, J.: El cambio tecnológico. Barcelona, 1992, pp. 65-81.

${ }^{67}$ Aunque se cuestione la capacidad predictiva del análisis histórico, ya que aunque sea posible determinar ciertas tendencias evolutivas, no se admite el fatalismo en el devenir humano. 
acontecimiento puntual y la oportunidad que implica se plasman en la idea griega de Kairos ${ }^{68}$, que contextualiza el acontecimiento o su oportunidad favorable mediante una simultaneidad de sucesiones bidireccionales de historias, descripciones y relaciones coyunturales.

Se concluye, por lo comentado en este apartado, que la unidad temporal de trabajo que usualmente utiliza y acepta el historiador académico es el periodo dinámico, o sea, el tiempo considerado bajo la forma de sucesión y duración. Así pues, el tiempo empleado en la investigación histórica es el cronológico o la correcta datación para la ordenación y explicación de los acontecimientos ${ }^{69}$, un tiempo común y exógeno a los historiadores ${ }^{70}$. Este marco temporal coincide, como se ha venido afirmando, con la idea latente en el dios griego Chrónos. Frente a esta categoría temporal se encuentra Kairós o momento favorable, el cual tradicionalmente ha sido marginado por influencia del pensamiento Occidental. Influencia que ha estado fundamentada en las creencias cristianas en las que Dios revelaba los capítulos decisivos (momentos y oportunidades) ${ }^{71}$. La idea griega de Kairos, remite en el relato histórico a un tiempo rizomático de simultaneidad de sucesiones reversibles en función de la narración del historiador. Es decir, un análisis de los sucesos históricos en función de su contexto y de su oportunidad de éxito o de fracaso, vinculándolos bidireccionalmente con procesos paralelos, sucesivos o pasados. Con un tiempo rizomático la unidad temporal de análisis del historiador es el momento favorable.

El tiempo cronológico, Chrónos, ha sido el habitual en el análisis histórico, como un tiempo que ordena absolutamente los acontecimientos posibilitando su relación temporal sincrónica o diacrónica. Esta ordenación absoluta sólo es posible dentro del Relativismo fisico a través de una relación causal, que impone la necesidad de la sucesión descrita por la fuerza del sujeto histórico o de los acontecimientos pasados. Este tiempo cronológico es externo al análisis descrito sucesivamente para ser posible la ordenación absoluta y tiene su auge con la objetivación de los acontecimientos, lo cual permite numerarlos mediante su datación y su ordenación.

\footnotetext{
${ }^{68}$ Campillo, A.: Op. cit., pp. 33-70.

69 Koselleck, R.: Futuro pasado. Barcelona, 1993, p. 14.

${ }^{70}$ Braudel, F.: Op. cit., Capítulo II.

71 Jaspers, K.: Origen y meta de la Historia. Barcelona, 1995, pp. 20-21
} 
El tiempo cronológico supone que el agente histórico, dada su posición de poder y la dinámica irreversible de las decisiones pasadas, domina o comprende la situación que le rodea dirigiéndola con sus decisiones. También supone que el historiador refleja objetiva y unívocamente las decisiones y consecuencias históricas en una relación causal. Es decir, se entiende el relato histórico como la descripción de la sucesión ordenada e irreversible de acontecimientos pasados cuantificados desde el presente. El tiempo es, pues, la imagen del movimiento numerado representado por Chrónos.

El tiempo rizomático, representado por el mito griego de Kairós, por el contrario, defiende el momento favorable como unidad temporal de trabajo. Su origen, ya no está en la objetivación, cuantificación y necesidad de los acontecimientos pasados, sino en la posibilidad de los mismos. Se parte, no de la fuerza del agente o de la dinámica históricos, sino de su contextualización, donde el agente histórico sólo domina la técnica y, por tanto, su nivel de comprensión y de control de la situación es limitado. Al tecnificarse la actuación histórica, la misma se explica por el momento en que ocurre o no ocurre a partir de la oportunidad. Cada acontecimiento ya no se ordena, con un tiempo rizomático, de forma absoluta, sucesiva e irreversible, sino que se vincula con el contexto en que ocurre el acontecimiento, con las sucesiones paralelas, pasadas y futuras de otros acontecimientos de forma bidireccional y con el conocimiento e hipótesis del historiador que lo analiza, justificándose su éxito o fracaso por el momento favorable para dicho acontecer. No interesa una descripción cuantitativa de la sucesión del acontecer histórico, sino una narración que justifique dicho acontecer. Por tanto, se pierde la objetividad y universalidad de la explicación e interpretación en tiempo cronológico, a cambio de una narración subjetiva y más o menos crerble en función de las fuentes históricas vinculadas y la naturaleza crítica humana, que busca la simplicidad. En este último caso novela y relato histórico no tienen una frontera definida y depende de la credibilidad de la retórica utilizada la calificación de la narración. Al contrario de con tiempo cronológico, donde la descripción objetiva, numérica y contrastada del pasado se distingue de la ficción argumentada.

\section{CONCLUSIÓN}

El marco temporal es el eje de cualquier investigación histórica. En este artículo se analizan dos posibilidades de unidades temporales en el relato histórico: 
el tiempo cronológico, que se centra en el período dinámico, y el tiempo rizomático, que se basa en el momento favorable. Ambas unidades tienen paralelos en la deificación griega del tiempo, representadas respectivamente por el dios de la sucesión y el envejecimiento Chrónos, y por Kairós o personificación de la oportunidad o momento favorable.

El período ha monopolizado desde el siglo XIX la categoría temporal de trabajo del historiador, mediante la objetivación, la cuantificación y la ordenación irreversible de los acontecimientos, estableciéndose relaciones causales desde el presente. Sin embargo, introduciendo la tecnificación en la actuación del agente histórico, el éxito de cualquier decisión o acontecimiento depende del momento favorable para la misma, dado por el contexto, tanto presente, como pasado, como futuro. De manera que se sustituye la necesidad de la relación objetiva histórica por su posibilidad y subjetividad.

El objetivo ha sido mostrar dos enfoques alternativos de análisis históricos: el basado en el período del análisis de la sucesión irreversible y la duración numérica de los acontecimientos, y el basado en el instante de la narración contextualizada y bidireccional del acontecer histórico. 